\title{
INCIDENCIA DE CISTICERCOSIS PORCINA EN EL DISTRITO DE MATAPALO, TUMBES
}

\author{
Carla Mena A. ${ }^{1}$, Armando González Z. ${ }^{2,3}$, Néstor Falcón P. ${ }^{2}$, \\ Teresa Bernal R. ${ }^{2}$ y Viterbo Ayvar P. ${ }^{1}$
}

\section{Abstract}

It was evaluated the prevalence and the incidence rate (force of morbidity of cysticercosis) in the period of January-April, 2000 in the porcine population of Matapalo's village (Zarumilla, Tumbes). In the first sampling, 922 animals older than 3 months were evaluated and 284 resulted positive representing a prevalence of $30.8 \pm 3.0 \%$. The second sampling, carried out three months later on 778 animals reported a prevalence of $20.8 \pm 2.9 \%$. A total of 314 negative animals at the first sampling were evaluated in the second sampling and 36 seroconverted to the EITB test resulting in an accumulated incidence of $11.5 \pm 3.5 \%$. A number of risk factors were analyzed for the prevalence of porcine cysticercosis finding out that village, age and sampling represented a factor of risk to find a positive animal. Similarly, several factors relating to incidence were analized and was found that the variables village, age, immunological condition of the mother, and sex represented risk factors to get the disease.

Key words: cysticercosis, prevalence, incidense, risk factors

\section{Resumen}

Se evaluó la prevalencia y la tasa de infección o la fuerza de morbilidad de la cisticercosis expresada como incidencia acumulada en el periodo de enero a abril del 2000 en la población porcina del distrito de Matapalo (Zarumilla, Tumbes). En el primer muestreo se evaluaron 922 cerdos mayores de 3 meses (con excepción de hembras en gestación avanzada), encontrándose una prevalencia del $30.8 \pm 3.0 \%$. En el segundo muestreo se evaluaron 778 cerdos, encontrándose una prevalencia de $20.8 \pm 2.9 \%$. Un total de 314 animales negativos al primer muestreo fueron evaluados en el segundo muestreo y 36 seroconvirtieron a la prueba de EITB, lo que resultó en una incidencia acumulada de 11.5 $\pm 3.5 \%$. Se analizaron factores de exposición para la prevalencia de la cisticercosis porcina encontrándose que las variables caserío, edad y muestreo representaron un factor de riesgo para encontrar un animal positivo. Con respecto a la incidencia, se encontró que las variables caserío, edad, condición inmunológica de la madre y sexo representaron un factor de riesgo para contraer la enfermedad.

Palabras clave: cisticercosis, incidencia, prevalencia, factores de riesgo

\footnotetext{
${ }^{1}$ Práctica privada

${ }^{2}$ Laboratorio de Medicina Veterinaria Preventiva, FMV-UNMSM

${ }^{3}$ E-mail: agonzalesz@vet.unmsm.edu.pe
} 
INTRODUCCIÓN

La crianza de cerdos en el Perú, fuera de aquella de tipo comercial intensiva, representa un rubro de gran importancia para el poblador rural. El cerdo se emplea para "ahorrar" dinero, de manera que los campesinos tienen un producto de fácil comercialización que pueden vender cuando requieren liquidez. La inversión en la crianza de este tipo de cerdo es de baja cuantía y el costo de mantenimiento es mínimo.

La cisticercosis es una de las principales enfermedades zoonóticas parasitarias en el país. La teniosis y la cisticercosis, ocasionadas por la Taenia solium, prevalecen tanto en áreas urbanas como rurales y se encuentran asociadas a prácticas tradicionales de crianza de cerdos, malas condiciones sanitarias e higiénicas, ignorancia y pobreza (Sarti y Gutierrez, 1986).

La cisticercosis causa grandes pérdidas económicas a los productores cuando los cerdos se comercializan por vías formales (centros de beneficio), debido a que son decomisados y eliminados sin que los productores reciban compensación alguna. Esto ha devenido en la aparición de mataderos ilegales y sistemas de comercialización de tipo informal que favorecen la dispersión de la teniasis y la cisticercosis (González et al., 1996).

Estudios epidemiológicos de cisticercosis, basados en pruebas serológicas en porcinos, han revelado prevalencias disímiles en las tres regiones del país. En la Costa se encontró una prevalencia del 5.2\% en Monte Redondo, Piura (Gavidia, 1993). En la Sierra, donde se han realizado la mayor cantidad de estudios se reportan prevalencias que varían desde $31 \%$ en la provincia de Andahuaylas, Apurímac (Ramos, 1999) a 72\% en la provincia de Quilcas, Junín (Bernal, 1996). En la Selva norte las prevalencias han variado de 43\% en Maceda, Tarapoto (Castro, 1991) a $49 \%$ en Churusapa, Tarapoto (García et al., 1996).
Los estudios epidemiológicos permiten estudiar la presentación natural de las enfermedades y el reconocimiento de los factores que permiten identificar las poblaciones en riesgo. Por otro lado, los estudios de incidencia permiten conocer la tasa de infección o fuerza de morbilidad de la enfermedad, cuantificando durante un periodo de tiempo a los individuos de una población que desde el estado libre de enfermedad pasan al de enfermo. Hasta la fecha, han realizado únicamente estudios de prevalencia en el país, los que han permitido medir la presencia de la enfermedad en un determinado momento. La realización de estudios de incidencia permitirá conocer la tasa de infección o fuerza de morbilidad de la cisticercosis en zonas endémicas, al expresar el número de casos nuevos que aparecen en una población durante un periodo de tiempo, y de esa forma determinar nuevas estrategias de control.

El presente estudio pretende determinar la incidencia de la cisticercosis en un periodo de tres meses en los siete caseríos que conforman el distrito de Matapalo, Tumbes.

\section{Materiales y Métodos}

\section{Lugar de estudio}

El estudio se desarrolló en siete caseríos del distrito de Matapalo (Matapalo, Quebrada Seca, Tutumo, Totora, Isla Noblecilla, Leandro Campo y Nuevo Progreso), provincia de Zarumilla, departamento de Tumbes. Estos caseríos carecen de luz, agua potable y servicios de alcantarillado, y el acceso es a través de una trocha carrozable. Los pobladores obtienen el agua de riachuelos y ríos cercanos.

\section{Animales y muestras}

Se recolectaron muestras de sangre (4-8 ml) de cerdos criollos mayores de 3 meses de edad, con excepción de hembras con gestación evidente. Los animales fueron aretados para facilitar su identificación. 
Las muestras de sangre se colectaron de la vena cava anterior izquierda (Leman y Straw, 1986) en tubos de sangrado al vacío (sistema vacutainer) anotándose el número de arete, sexo, edad, propietario y la fecha de muestreo. Las muestras fueron centrifugadas a 3,800 rpm x 6 minutos. Los sueros se distribuyeron en tres alicuotas de $1.5 \mathrm{ml}$ y fueron almacenados a $-20^{\circ} \mathrm{C}$ hasta su análisis.

Se hicieron dos muestreos con un intervalo de tres meses (enero y abril del 2000). La incidencia se obtiene, en principio, con animales que son muestreados en las dos oportunidades; por tanto, ante un recambio poblacional agresivo de $80 \%$ anual, se tuvo que considerar un intervalo lo suficientemente largo para detectar nuevas infecciones y lo suficientemente corto como para que el recambio poblacional no atente contra el objetivo del proyecto.

\section{Serología}

El diagnóstico de cisticercosis se realizó mediante el empleo de la prueba de Electro Inmuno Transferencia Blot (EITB) o Western Blot, que permite detectar la presencia de anticuerpos contra la forma larvaria de la T. solium (Tsang et al., 1989; González et al., 1990). La presencia de una o más bandas en las muestras de sueros fue indicativo de anticuerpos contra cisticercos T. solium y por tanto, los animales se consideran positivos. Además, los animales jóvenes ( $<6$ meses) y con madres positivas a la prueba de EITB que aumentaron el número de bandas en el segundo muestreo se consideraron como casos nuevos, por considerar que la respuesta inicial pudo ser por inmunidad pasiva.

\section{Análisis de datos}

Se determinó la prevalencia en cada muestreo, así como la incidencia acumulada (IA), mediante la fórmula indicada por Thrusfield (1990).

$$
\mathrm{IA}=\frac{\text { Casos nuevos en un periodo }}{\text { Población expuesta }}
$$

Se analizaron los factores de riesgo asociados a cada muestreo transversal (prevalencias) y a la aparición de casos nuevos (incidencia). En el caso de la prevalencia se empleó una ecuación de estimación generalizada. Esta ecuación estimó modelos de series lineales de tiempo usando cuadrados mínimos de generalización viable (Stata Reference Manual, 2001; Zeger y Liang, 1988). Los resultados de prevalencia e incidencia se expresaron con intervalos de confianza del $95 \%$.

\section{Resultados}

En el primer muestreo se trabajó con 922 animales y se determinó una prevalencia de 30.8 $\pm 3.0 \%$, en tanto que en el segundo muestreo se evaluó a 778 animales, resultando en una prevalencia de $20.8 \pm 2.9 \%$ (Cuadro 1 ).

De los 638 animales negativos al primer muestreo, 314 fueron nuevamente evaluados en el segundo muestreo. De estos, 36 seroconvirtieron a la prueba de EITB, lo que resultó en una incidencia acumulada de 11.5 $\pm 3.5 \%$ para el periodo enero-abril del 2000 (Cuadro 2).

El análisis de factores de exposición para la prevalencia de la cisticercosis porcina, usando la Ecuación de Estimación Generalizada (GEE) indicó que las variables edad y muestreo se comportaron estadísticamente diferentes y que, por lo tanto, representaron factores de riesgo para encontrar un animal positivo. El Cuadro 3 muestra en detalle el valor de Odds Ratio y sus respectivos intervalos de confianza de las variables de exposición.

El análisis de factores de exposición para la incidencia de la cisticercosis porcina que se realizó mediante la regresión logística pone en evidencia que las variables caserío, edad, condición inmunológica de la madre y 
Cuadro 1. Población porcina muestreada y positiva a cisticercosis en la zona de Matapalo, Tumbes, utilizando el método de Electro Inmuno Transferasa Blot (EITB). (Periodo enero-abril, 2000)

\begin{tabular}{|c|c|c|c|c|c|c|}
\hline \multirow{3}{*}{ Caserío } & \multicolumn{3}{|c|}{ Primer Muestreo } & \multicolumn{3}{|c|}{ Segundo Muestreo } \\
\hline & \multirow{2}{*}{$\begin{array}{c}\text { Muestreados } \\
\text { (n) }\end{array}$} & \multicolumn{2}{|c|}{ Positivos } & \multirow{2}{*}{$\begin{array}{c}\text { Muestreados } \\
\text { (n) }\end{array}$} & \multicolumn{2}{|c|}{ Positivos } \\
\hline & & $(\mathrm{n})$ & $(\%)$ & & $(\mathrm{n})$ & $(\%)$ \\
\hline Isla Noblecilla & 22 & 9 & 40.9 & 19 & 9 & 47.4 \\
\hline Leandro Campo & 119 & 28 & 23.5 & 93 & 8 & 8.6 \\
\hline Matapalo & 185 & 88 & 47.6 & 138 & 43 & 31.2 \\
\hline Nuevo Progreso & 236 & 85 & 36.0 & 216 & 50 & 23.1 \\
\hline Quebrada Seca & 48 & 18 & 37.5 & 53 & 21 & 39.6 \\
\hline Totora & 37 & 11 & 29.7 & 23 & 2 & 8.7 \\
\hline Tutumo & 275 & 45 & 16.4 & 236 & 29 & 12.3 \\
\hline Total & 922 & 284 & $30.8 ? 3.0^{1}$ & 778 & 162 & $20.8 ? 2.9$ \\
\hline
\end{tabular}

${ }^{1}$ Promedio ? intervalo de confianza del 95\%

Cuadro 2. Incidencia de cisticercosis porcina en siete caseríos del distrito de Matapalo, Tumbes (Periodo enero-abril, 2000)

\begin{tabular}{|c|c|c|c|}
\hline Caserío & $\begin{array}{c}\text { Negativo al } 1^{\text {er }} \text { muestreo } \\
\text { (n) }\end{array}$ & $\begin{array}{c}\text { Positivo al } 2^{\text {do }} \text { muestreo } \\
\text { (n) }\end{array}$ & $\begin{array}{l}\text { Frecuencia } \\
\qquad(\%)\end{array}$ \\
\hline Isla Noblecilla & 10 & 6 & 60.0 \\
\hline Leandro Campo & 41 & 2 & 4.9 \\
\hline Matapalo & 45 & 4 & 8.9 \\
\hline Nuevo Progreso & 68 & 17 & 25.0 \\
\hline Quebrada Seca & 14 & 2 & 14.3 \\
\hline Totora & 13 & 1 & 7.7 \\
\hline Tutumo & 123 & 4 & 3.3 \\
\hline Total & 314 & 36 & $11.5 ? 3.5^{1}$ \\
\hline
\end{tabular}

${ }^{1}$ Promedio ? intervalo de confianza del 95\%

sexo se comportan estadísticamente diferentes y que por lo tanto representaron un factor de riesgo para contraer la enfermedad (Cuadro3).

Los caseríos de Nuevo Progreso, Quebrada Seca y Totora representaron un factor de riesgo en relación al caserío de Isla Noblecilla. El aumento de la edad tuvo una relación inversa con la aparición de casos nuevos, es decir, los animales se infectaron a una edad temprana (5-8 meses). Por último, al evaluar la condición inmunológica de la madre, se observó que las crías provenientes de madres positivas tuvieron mayor probabilidad de dar una respuesta positiva a la prueba diagnóstica de EITB. 
Cuadro 3. Resultados de Odds Ratio (OR) a partir de la evaluación del efecto de las variables caserío, condición inmunológica de la madre, edad, sexo y muestreo, sobre la prevalencia e incidencia de la cisticercosis porcina. Matapalo, Tumbes. 2000

\begin{tabular}{|c|c|c|c|c|c|c|}
\hline \multirow{3}{*}{ Variable de exposición } & \multicolumn{3}{|c|}{ Prevalencia } & \multicolumn{3}{|c|}{ Incidencia } \\
\hline & \multirow{2}{*}{ OR } & \multicolumn{2}{|c|}{ IC del $95 \%$ del OR } & \multirow{2}{*}{ OR } & \multicolumn{2}{|c|}{ IC del $95 \%$ del OR } \\
\hline & & Inferior & Superior & & Inferior & Superior \\
\hline \multicolumn{7}{|l|}{ Caserío (I. Noblecilla) } \\
\hline Caserío (L. Campo) & 0.25 & 0.13 & 0.51 & 1.03 & 1.00 & 1.44 \\
\hline Caserío (Matapalo) & 0.87 & 0.46 & 1.64 & 1.05 & 1.00 & 1.51 \\
\hline Caserío (N. Progreso) & 0.55 & 0.30 & 1.02 & 1.22 & 1.03 & 4.5 \\
\hline Caserío (Q.Seca) & 0.62 & 0.29 & 1.34 & 1.07 & 1.01 & 2.32 \\
\hline Caserío (Totora) & 0.38 & 0.15 & 0.93 & 1.13 & 1.01 & 4.76 \\
\hline Caserío (Tutumo) & 0.20 & 0.11 & 0.39 & 1.01 & 1.00 & 1.14 \\
\hline \multicolumn{7}{|l|}{ Sexo (Hembra) } \\
\hline Sexo (Macho) & 1.00 & 0.80 & 1.24 & 4.20 & 1.92 & 23.58 \\
\hline \multicolumn{7}{|l|}{ Condición madre (-) } \\
\hline Condición madre (+) & 0.96 & 0.91 & 1.01 & 1.71 & 1.07 & 84.34 \\
\hline \multicolumn{7}{|l|}{ Edad (0-4 m) } \\
\hline $\operatorname{Edad}(5-8 \mathrm{~m})$ & 0.93 & 0.69 & 1.25 & 6.03 & 2.15 & 67.73 \\
\hline Edad (9-12 m) & 2.33 & 1.63 & 3.32 & 7.38 & 1.47 & 34074.34 \\
\hline Edad $(>12)$ & 3.59 & 2.50 & 5.16 & 1.46 & 1.05 & 22.18 \\
\hline \multicolumn{7}{|l|}{ Muestreo $\left(2^{\circ}\right)$} \\
\hline Muestreo $\left(1^{\circ}\right)$ & 2.06 & 1.63 & 2.6 & & & \\
\hline
\end{tabular}

\section{Discusión}

El presente estudio representa uno de los trabajos pioneros sobre incidencia de la cisticercosis porcina en el Perú. El estudio consideró dos muestreos con un intervalo de tres meses; intervalo lo suficientemente largo para detectar nuevas infecciones y lo suficientemente corto como para que el recambio poblacional no atente contra el objetivo del proyecto.
No existen estudios previos en el país para poder realizar comparaciones con el porcentaje de incidencia encontrado en este estudio $(11.5 \pm 3.5 \%)$. Por otro lado, estos resultados no pueden generalizarse, dadas las características geográficas, climáticas y costumbristas de la zona estudiada, aún cuando las prevalencias de la enfermedad muestran que esta zona se clasifica como endémica a la cisticercosis porcina (30.8 y $20.8 \%$ para el primer y segundo muestreo, respectivamente). 
Los resultados del análisis de factores de riesgo varían de acuerdo a las variables bajo estudio. La mayor probabilidad de encontrar casos nuevos en algunos caseríos depende del consumo de heces humanas contaminadas con huevos o proglótidos de $T$. solium por parte de los porcinos. Esto está directamente relacionado con la falta de higiene de la población humana que no elimina adecuadamente sus heces, contaminando el ambiente, y por otro lado, que facilita el acceso de los cerdos a las heces humanas. Guezala (2001) puso en evidencia la existencia de mayor cantidad de cerdos infectados cuando estos se criaban alrededor de las casas de personas portadoras de tenia.

La evaluación de la edad como factor de riesgo muestra que los animales jóvenes son los más expuestos, ya que son más susceptibles de contraer la infección (Cordero del Campillo y Rojo, 1999). Los animales desarrollan la enfermedad en su juventud y se mantienen así hasta la edad adulta. Por otro lado, los resultados indican que el sexo es un factor de riesgo para la presencia de nuevos casos, ya que los machos tienen mayor probabilidad de infectarse. Sin embargo, no se han reportado hasta el momento diferencias entre sexos para contraer la cisticercosis.

La condición inmunológica de la madre representa un factor de riesgo para contraer la enfermedad. Hay una gran posibilidad de que madres positivas estuvieran expuestas a medio ambientes contaminados, y que sus crías también estuvieran expuestas a estos ambientes. A esto se suma el hecho de que los anticuerpos que son transferidos de la madre a la cría por inmunidad pasiva aparentemente no son protectivos. Este criterio se refuerza con los hallazgos obtenidos en el presente estudio, en donde se encuentra que animales positivos a EITB para cisticercosis en el primer muestreo ( 2 bandas) aumentan el número de bandas reactivas en el segundo muestreo (4 bandas), lo cual solamente puede ser explicado por la exposición a huevos o proglótidos de T. solium.
El presente estudio ha tratado de aportar información sobre la tasa de infección o fuerza de morbilidad de la cisticercosis en zonas endémicas a fin de responder a la necesidad de contar con una herramienta que permita evaluar el efecto de diferentes estrategias de control a nivel de campo (tratamientos antihelmínticos en poblaciones humanas y porcinas); además de medir la presión de infección y/o contaminación ambiental con huevos de T. solium.

\section{Conclusiones}

- La incidencia de cisticercosis porcina en el periodo enero-abril del 2000 en el distrito de Matapalo, Tumbes fue de $11.5 \pm$ $3.5 \%(36 / 314)$.

- La prevalencia de cisticercosis en el primer y segundo muestreo fue de $30.8 \pm$ $3.0 \%$ y $20.8 \pm 2.9 \%$.

- Los factores caserío, edad, condición inmunológica de la madre y sexo asociados a la incidencia de cisticercosis se comportaron estadísticamente diferentes y por lo tanto representaron un factor de riesgo para contraer la enfermedad.

- Los factores caserío, sexo y muestreo asociados a la prevalencia de cisticercosis se comportaron estadísticamente diferentes, y por lo tanto representaron un factor de riesgo para contraer la enfermedad.

\section{LITERATURA CITADA}

1. Bernal, T. 1996. Evaluación de la cisticercosis porcina en el distrito de Quilcas, Huancayo. Tesis de Bachiller. Facultad de Medicina Veterinaria, Univ. Nacional Mayor San Marcos. 45 p.

2. Castro, V. 1991. Prevalencia de cisticercosis porcina: comparación de examen de lengua y EITB en Maceda, Tarapoto, departamento de San Martín. Tesis de Bachiller. Facultad de Medicina Veterinaria, Univ. Nacional Mayor de San Marcos. Perú. 32 p. 
3. Cordero del Campillo, M.; F. Rojo. 1999. Parasitología veterinaria. Mc Graw-Hill-Interamericana. España. p 493-495.

4. García, H.H.; R. Gilman; A.E. González; M. Verástegui; The Cisticercosis Working Group in Peru. 1999. Epidemiology of Taenia solium infection in Peru. En: Taeniasis/Cisticercosis by Taenia solium. $2^{\mathrm{a}}$ ed. H.H. García; S.M. Martínez (eds). p 297-305. Editorial Universo. Lima, Perú.

5. Gavidia, C. 1993. Prevalencia de cisticercosis porcina en un pueblo de la Costa Norte: Monte Redondo (Piura). Tesis de Bachiller. Facultad de Medicina Veterinaria, Univ. Nacional Mayor San Marcos. Lima. 38 p.

6. González, A.E.; V. Cama; R. Gilman; V. Tsang; J.B. Pilcher; A. Chavera; M. Castro; T. Montenegro; M. Verástegui; E. Miranda; E. Bazalar. 1990. Prevalence and comparison of serologic assay, necropsy and tongue examination for the diagnosis of porcine cisticercosis in Peru. Am. J. Trop. Med. Hyg. 43:194- 199.

7. González, A.E.; C. Gavidia; R.H. Gilman; H.H. García; N. Falcón; T. Bernal. 1996. Tratamiento de la cisticercosis porcina. En: Teniasis Cisticercosis por Taenia solium. H.H. García; S.M. Martínez (eds). p 109-120. Editorial Universo. Lima, Perú.
8. Guezala, C. 2001. Estudio de la distribución geográfica de la teniasis/cisticercosis y su relación con la dinámica de infección de la enfermedad. Tesis Bachiller. Facultad de Medicina Veterinaria, Univ. Nacional Mayor de San Marcos. Lima. 84 p.

9. Leman, A.D.; B. Straw. 1986. Diseases of swine. $6^{\text {th }}$ ed. Iowa State University Press. Ames Iowa, USA. p 211-213.

10. Ramos, D. 1999. Seroprevalencia de cisticercosis porcina en las villas de Occollo y Anaccma, provincia de Andahuaylas, departamento de Apurímac. Tesis de Bachiller. Facultad de Medicina Veterinaria, Univ. Nacional Mayor San Marcos. Lima. 51 p.

11. Sarti, E.; M. Gutiérrez. 1986. La teniasis y cisticercosis en México. Salud Pública de México 28: 556-561.

12. Stata Reference Manual. 2001. Release 7. Vol. 4. Stata Press College Station, Texas. p 326.

13. Thrusfield, M. 1990. Epidemiología veterinaria. Ed. Acribia. Zaragoza, España. p 42-43.

14. Tsang, V.; J.A. Brand; A.E. Boyer. 1989. An enzyme-linked inmunoelectro-transfer blot assay and glycoprotein antigens for diagnosing human cysticercosis (Taenia solium). J. Infection Dis. 159: 50-59.

15. Zeger, S.L.; Y. Liang. 1988. Models for longitudinal data: a generalizad estimating equation approach. Biometrics 44: 1049-1060. 